blood loss. and may he of interest in retrospect. when compared with haemoglobin readings during the phase of shock.

\section{Suggested Procedure}

(a) General duties orderly or clerk to complete details on top of page 1 for each case on admission to resuscitation wards.

(b) Nurse or trained nursing orderly to complete sections $\mathrm{A}, \mathrm{B}$, and $\mathrm{C}$ under supervision. This may be done while he is waiting for the blood or plasma to warm up and while he watches it pouring in.

(c) Resuscitation officer, (i) on admission, to take rapid history, do brief examination, and order treatment; (ii) introduce needle and collect blood for haemoglobin estimation ; (iii) later read $\mathrm{A}$ and $\mathrm{B}$ and add any further comments and notes, indicating his views of the severity of the various symptoms, signs, and complaints, and ordering further treatment; (iv) complete later notes, after two to five days if possible.

(d) Nurse or trained nursing orderly to accompany severe cases during operation, to supervise transfusion, and to complete operation and anaesthetic notes and records of blood loss at operation. Where possible the nurse or orderly who has resuscitated the case should be detailed for this work to ensure continuity of treatment and interest, but if one cannot be spared the co-operation of the anaesthetist should be invited.

\section{Summary}

The desirability of a standard record card for cases of shock in E.M.S. and military hospitals is stressed.

A resuscitation record card designed for practical utility and suitable for statistical research is described and illustrated. Copies of this card are readily obtainable.

It was from suggestions of Lieutenant (now Major) $\mathrm{H}$. W. Rodgers in January, 1940, that my blood transfusion record card was greatly improved.

My thanks are due to Major H. L. Marriott and Captain A. Kekwick for many helpful suggestions, and to Majors Hadley and Kimbell for repeated assistance in remodelling and improving the card.

Latterly I have had most useful advice from Prof. J. A. Ryle and Colonel L. E. H. Whitby, O C the Army Blood Transfusion Service, as a result of which the card has been much shortened and its objective focused on results of treatment. Finally, a number of its details have been modified on advice from Prof. T. B. Davie, Dr. H. F. Brewer, and Lieut. J. B. Hurll.

In making these acknowledgments I must, however, accept full responsibility for production of this paper.

\section{REFERENCES}

Brennan, H. J. (1940). British Medical Journal. 1. 1047

Brewer, H. F., Maizels. M. Oliver, J. O., and Vaughan. I. (1940) Ibid., 2, 48 Brittain. H. A., and Latter, K. A. (1940), Ibid.. 2, 284

Challenor, L. T. (1940), J. R.A.M.C., 75, 53

Jones, F. Avery, and Morgan, C. Naunton (1938). St. Bart's Hosp. Rep. 71, 83.

Keith, N. M. (1919). Med. Res. Cnci. Sp. Rep. Ser. No. 26, p. 36. London. McDowall, R. J. S. (1940). British Medical Journal, 1, 919.

Moon, V. H. (1938). Shock and Related Capillary Phenomena, London.

Riddell, V. H. (1939). Blood Transfusion, London.

Robertson, O. H., and Bock, A. V. (1919). Med. Res. Cncl. Sp. Rep. Ser. No.

25, p. 213 , London.
Scudder, J. (1940). Shock: Blood Studies as a Guide to Therapy, Philadelphia.

M. Schmouchkovitch (Thèse de Paris, 1940, No. 284) records twenty-one cases, in patients aged from 11 to 53 , indicating the importance of inherited or acquired syphilis in the causation of appendicitis. Clinically there are symptoms of appendicitis-tenderness at McBurney's point and muscular resistance-which yield to anti-syphilitic treatment. Anatomically there may be a characteristic diffuse lymphocytic infiltration in the appendix, a sclero-gummatous process destroying the whole organ, gummatous ulceration of the wall of the appendix, or a plasmocytic granuloma, which is the last stage of a gumma which has perforated the muscular wall of the appendix. Lastly, the Treponema pallidum has been found in the appendix.

\section{SARCOIDOSIS}

\section{SOME SPECULATIONS AS TO THE STAGES OF INFECTION IN GENERAL}

\author{
BY
}

\section{G. ERIC LEWIS, M.A., M.B., M.R.C.P.}

Honorary Physician to the Hull Royal Infirmary and the Scunthorpe and District War Memorial Hospital

Considerable attention has recently been devoted to the condition described as the "sarcoidosis of Boeck." This paper gives details of an unusual case in which there were signs and symptoms suggestive of a "visceralization" in the central nervous system, producing the clinical syndrome known by the name of Adie.

The mere report of an unusual case is scarcely novel, but it appears that a consideration of the pathology and possible aetiology of the sarcoidosis of Boeck may well lead to an understanding of the mechanism of infection and immunity in general. Some discussion of these possibilities is attempted after a description of the particular patient.

\section{Case Record}

Mrs. A. provided a diagnostic problem lasting for nearly two years from November, 1936. She was 53 years of age when she was referred to my clinic at the Hull Royal Infirmary in that month. She had for three months past been complaining of a "blurred patch" in the lower part of the field of vision of the left eye. Apart from occasional pains in her hips and back, she presented no other symptoms of any sort. A past history of so-called "muscular rheumatism" ten years ago was elicited, but she denied any other indispositions. On examination the pupils were found to be inactive-there being no response either to light or to accommodation-and she seemed to have a tendency to Rombergism. There was, however, no sensory loss to pinprick, postural change. or vibration. The grip of both hands was firm, strong. and equal, but a slight tremor of a coarse sort and of "intention "type was noticed. The gait was fair, but although the arm-jerks were normal both ankle-jerks were absent and also the right knee-jerk. No other grossly abnormal physical signs were detected.

She was admitted to the Hull Royal Infirmary under my care on November 16,1936, and it was found that the Wassermann reaction of the blood was negative. The cerebrospinal fluid was not under pressure and was not abnormal in respect of its cell, protein, or glucose content. The Wassermann reaction of the fluid was also negative. Further clinical examination showed sluggishness of both biceps-jerks and, later, probable absence of the biceps- and supinator-jerks. Perimetry confirmed the constriction of the field of vision of the left eye, and ophthalmoscopy presented a confusing picture. The left optic disk seemed pale and the left retinal vessels were narrowed. The appearances were suggestive of secondary optic atrophy. The veins of the right retina were engorged and the right optic disk appeared to be affected by a mild papilloedema. These findings were confirmed by the ophthalmic surgeon (Dr. Stenhouse Stewart). A radiograph of the skull (Dr. J. E. Bannen) was reported upon as showing no abnormality. Apart from a suggestion of possible neuromyelitis optica no definite diagnosis could be formulated, and Mrs. A. left the Infirmary early in December, 1936. Later that month she consulted Dr. W. Russell Brain, who informed me that he considered her to be a casse of Adie's syndrome with tonic pupils and absent tendon-jerks.

The patient continued to attend my follow-up clinic, but her condition remained unchanged and no further symptoms were remarked upon until May, 1937. At this time both parotid glands began to swell. The enlargement was more pronounced on the left side than on the right, and it was not accompanied by pain, fever, or any constitutional disturbances. On June 19 the parotid swellings seemed quite unchanged. A degree of incoordination, as shown by finger-to-finger and finger-to-nose tests, was evident, but the other neurological findings, given above, were quite unaltered. A radiograph of the chest taken 
at this time was reported on as showing " no evidence of any tuberculous infiltration." She was admitted to the Hull Royal Infirmary again, and a portion of one parotid gland was removed for histological examination. The appearances were diagnosed by the pathologist (Dr. W. W. Adamson) as being due to tuberculosis, but examination of the section, while showing a granulomatous reaction with giant cells, failed to reveal any definite areas of caseation. The injection of an emulsion of the pulped tissue into a guinea-pig had been suggested, but this was not performed.

During her stay in hospital on this occasion the left optic disk still seemed very pale, but the outline of the right disk was perhaps rather less blurred than before. The defect in the field of vision was persistent and unchanged. The Mantoux reaction was negative as well with a 1 in 1,000 as with a 1 in 10,000 solution of old tuberculin. The parotid swellings gradually subsided, and the patient returned to her home on September 20, 1937.

When Mrs. A. was next seen she stated that "trouble with her eyes" began about the end of October, 1937. Later she also developed pains in and swelling of the small joints of the hands. She was readmitted to hospital on January 8, 1938 with a diagnosis of episcleritis. A small portion of corneal tissue was removed by Dr. Stenhouse Stewart, and the histological appearances were again considered by the pathologist to be those of tuberculosis. It was considered, however, for reasons similar to those previously mentioned, that the appearances were more probably those of the sarcoidosis of Boeck. The Mantoux reaction remained, as before, persistently negative. Clinical examination showed some periarticular swelling of the small joints of both hands, and the neurological changes were as previously described.

The inflammatory changes in the eyes subsided fairly satisfactorily, and the following report was given me by $\mathrm{Dr}$ Stenhouse Stewart: "The margins of the right optic disk are ill defined and the left disk is paler than normal, especially on the nasal side. This pallor has neither the appearance of a primary optic atrophy nor of a secondary one, the margins of the pale disk being well defined. This might, however, be possible in an atrophy secondary to a low degree of neuritis. The grosser sectoral field-loss of the left eye, being in the lower nasal quadrant, should correspond to the upper pole of the disk, but the left disk is no paler here than elsewhere. Is the visual lesion here possibly of the nature of chiasmal optoarachnoiditis?"

Further investigations included another radiograph of the chest, which was reported on as showing no disease at all. The hands were also examined radiologically, and showed no evidence of tuberculosis, arthritis, or any bony changes. The total white blood cell count was 15,000 per c.mm., the differential percentages being: polymorphs $65 \%$, lymphocytes $25 \%$ large mononuclears $6 \%$, and eosinophils $4 \%$. An Arneth count gave a "weighted mean" (polynuclear index) of 2.68. The sedimentation rate of the erythrocytes was definitely increased ( $36 \mathrm{~mm}$. in one hour), even although this rate was less than this $(25 \mathrm{~mm}$. in one hour) just before her discharge.

After her discharge the patient was seen again at my followup clinic. The eyes seemed much better, but the restriction in the visual field was unchanged. The periarticular changes in the hands had subsided, but the ankle-jerks and the right kneejerk were still absent. On the whole, however, her general condition was decidedly improved.

\section{Commentary}

This patient seems to have been affected by the sarcoidosis of Boeck, and I am not aware that any case of this condition showing neurological signs and symptoms has previously been reported. It is possible that similar obscure cases may be due to similar pathological changes. Certainly, the syndrome of Adie rarely appears to have any anatomical basis, and a review of suth cases (Adie's syndrome) might perhaps reveal further examples of the visceralization of the sarcoids. The above facts are merely adduced to illustrate the considerable variability of the manifestations of this condition. A full review of the subject is given by Snapper and Pompen (1938) in an excel- lent monograph, and this variability of symptomatology has also been stressed by Bodley Scott (1938).

It is now generally conceded that the uveo-parotitis of Heerfordt (1909) is a clinical variant of sarcoidosis. It was previously maintained that uveo-parotitis was invariabiy of tuberculous aetiology (Garland and Thomson, 1934), despite some evidence considered to point to the contrary (Lewis, Raines, and Stewart, 1936).

It is said that cases of sarcoidosis show a "positive anergy"-i.e., that they are more often Mantoux-negative than normal persons of the same age-and the findings in the case reported are consistent with this view. Lemming (1940) has failed to produce tuberculin-sensitiveness in cases of sarcoidosis even by the administration of living B.C.G. vaccine. Although such findings might be considered as evidence against a tuberculous aetiology for sarcoidosis, or rather as evidence of a considerable immunity to tuberculous infection, no explanation is given why a lesion in which no bacilli are demonstrable should not only persist for years but continue to develop in fresh sites. A remarkable case was reported by Wiseman (1938) in which tubercie bacilli were detected in the ulcers of the leg, said to be due to Boeck's sarcoid; but, as Ingram (1938) pointed out later, the evidence for the diagnosis of sarcoidosis was by no means conclusive.

The suggestion is made that Ranke's (1928) classification of tuberculosis may be extended and applied to almost any infection and that considerations of this sort may lead to an explanation of the above-mentioned facts. Ranke divided the tuberculous state into three stages, each characterized by its own type of tissue reaction. The primary stage, or stage of invasion, usually occurs during childhood for the majority of the population: it is symptomless and signless. In the secondary stage "tissue allergy" is said to develop, and, although it may also be symptomless, signs are present in the shape of positive tuberculin reactions. The lesions of this stage are exudative in nature-e.g., some cases of erythema nodosum, and some cases of uveo-parotitis, and even, possibly, some cases of Boeck's sarcoidosis. In the tertiary stage, with typical proliferative active tuberculous lesions, the skin tests with tuberculin may reveal a lessening of tissue hypersensitivity and an increase in tissue immunity.

It is common ground that any infection goes through very similar stages. There is an incubation period representing Ranke's first stage-the stage of invasion; and finally there is the fully developed disease. The problem of the second stage is less clear, but every physician sees many unexplained abortive cases which may well fall into this group. Cases of "threatened pneumonia." are not uncommon, and, in particular, cases of "meningism of uncertain aetiology," in which the tension of the cerebrospinal fluid is increased and yet no signs of definite disease can be made out in any part of the body, are often seen. Such cases, I consider, represent the second stage of an infection. Invasion has occurred, followed by an exudative tissue reaction, but the bodily defence mechanisms have in these particular cases overcome the invading organisms before the typical third-stage appearances of a recognized and recognizable disease have developed.

In view of Lemming's experiments it is permissible to conjecture that the second stage may be a non-specific one. Invasion may occur, and the second stage may actually be the development of either tissue allergy or anergy, according to the balance struck between the invading germs and the bodily defences. The type of tissue reaction may well be the same for all infections. Sarcoidosis may represent a typical second-stage lesion, as in my opinion does the particular type of it described as uveo-parotitis (Lewis, Raines, and Stewart, 1936). It is likely that a majority of 
cases are the response of the tissues (anergy or allergy) to a tuberculous invader, but it is more than likely that the second stage in infection is a non-specific one, and that the appearances of disease of a common sort are only produced when the balance between attack and defence is so disturbed as to allow of the development of the proliferative lesions of the third stage of disease, with the characteristic tissue immunity.

\section{Summary}

An unusual case of sarcoidosis is described, with " visceralization" in the nervous system, producing Adie's syndrome. Episcleritis and uveo-parotitis occurred later in the same patient.

A general discussion of the possible mechanisms of infection is attempted, and it is maintained that conditions such as sarcoiditis represent a non-specific second stage of disease.

REFEREN(ES

Garland, H. G., and Thomson. J. G. (1934). Lancet, 2, 743.

Hcerfordt, C. F. (1909). v. Graefes Arch. Ophthal., 70, 254

Ingram, J. T. (1938). British Medical Journal, 1. 872 .

Lemming. R. (1940). Acta med. scand., 103, 400 (quoted in British Medical Journal, 1941, 1, 92).

Lewis, G. E., Raines, R., and Stewart, D. S. (1936). Lancet, 2, 1204 Leivis, G. E., Raines). R., and (1928). Ausgewählte Schriften zur Tuberkulosepathologie, 6 ,
145, Berlin.

Scott, R. Bodley (1938). British Medical Journal, 2, 777.

Snapper, I., and Pompen, A. W. M. (1938). Pseudo-tuberculovis in Man, Part I, De Erven F. Bohn N.V., Haarlem.

Wiseman, R. H. (1938). British Medical Journal, 1, 673

\section{AN OUTBREAK OF ACUTE GASTRO- ENTERITIS AMONG TROOPS IN A LARGE TRAINING AREA PRELIMINARY REPORT}

BY

A. H. D. SMITH, M.C., T.D., M.B., Ch.B. Lieut.-Colonel, R.A.M.C.

AND

D. J. DAVIES, M.B., B.S., D.P.H. Captain, R.A.M.C.

In the midsummer of 1940 a few sporadic cases of enteritis of a very mild type occurred in a military camp, and despite all efforts no causal factor was discovered. None of the cases conformed to any of the known diseases with which diarrhoea of the small-intestinal type is associated. In several there was definite enlargement of the spleen, and in one case it was palpable for several weeks. It was never tender on palpation. Agglutination tests for typhoid and paratyphoid groups and tests for Brucella abortus. gave negative results.

From.the opening of the camp in the beginning of September, 1939, no case of typhoid, paratyphoid, er dysentery had occurred until this outbreak, and none has occurred since. T.A.B. inoculations had been carefully and widely carried out, and very few, if any, of the troops were not fully covered.

About the middle of September, 1940, a definite epidemic of gastro-enteritis began, and it still persisted at the time of writing (December 18). This was not limited to the military units, but existed among the civil population in the immediate vicinity, though apparently it has not been investigated by the civil authorities.

Every effort has been made to exclude the possibility that infection has been conveyed by foodstuffs, the milk supply, or the water supply. Repeated bacteriological examinations of these sources have been made, and all have been persistently negative for the typhoid group, the Salmonella group, staphylococci, and streptococci. Many specimens from the food served to all ranks in the camp were examined, including meat, sausage, margarine, cake, bread, and cheese. The water supply, which came from the mains of the near-by town, was chlorinated during the period of investigation.

Among a very large number of troops about 150 reported sick, and some 30 of these had to be admitted to hospital. In addition many had'had similar symptoms. but of such mild degree that they did not seek medical advice. In those cases admitted to hospital every effort was made to obtain a careful history of the illness and its opening phases, and thorough bacteriological examinations were made of the faeces and the blood in the acute phase and during the convalescent stage ten days after the onset and later. All bloods sent to the laboratory were cultured. It may be noted at once that the bacteriological examination of both blood and faeces was entirely negative. Blood counts were not done, and as we were unable to obtain specimens the vomit was not submitted to laboratory examination. The history of the illness was not constant, though $60 \%$ conformed very closely to what we can call the typical case. In such a case the patient retired to bed feeling perfectly fit. In the early hours of the morning he or she would wake up with intense and urgent vomiting, followed by diarrhoea of a very watery type. There was little malaise, and the most prominent symptoms apart from diarrhoea and vomiting were mild backache and a feeling of heaviness in the abdomen. The diarrhoea varied from a few motions a day to, in one case, twenty-six motions. The stools contained no blood or mucus; they were offensive, of the typical small-intestine ty.pe, and usually chocolatecoloured. The course of the illness in its acute stage was short. Most patients had a temperature varying from $99^{\circ}$ to $100^{\circ}$ for from twenty-four to thirty-six hours. A few had a higher temperature, but none over $101^{\circ}$, and in a few cases the pyrexia persisted for seventy-two hours. There was no prostration in any case, and immediately after the acute phase all patients complained of hunger and asked for food. Convalescence was smooth and rapid, and only a few cases relapsed. Most of those infected were fit to return to duty in about a week from the onset. During the acute stage the tongue was slightly furred; redness of the fauces was often seen; there was no skin eruption or epistaxis; and abdominal palpation revealed nothing except splashing in the right iliac fossa. The spleen was never palpable. There was no distinctive feature in the pulse rate.

Atypical cases had vomiting and no diarrhoea, or diarrhoea and no vomiting, the clinical course otherwise being similar to that of the typical case. The bulk of the cases were ambulatory. In a number of atypical cases there were prodromal symptoms of a few hours' duration. These consisted of a feeling of malaise and shivering. In a series of 76 cases 50 had diarrhoea and vomiting, 6 vomiting only, and 20 diarrhoea only. The epidemic was still prevalent at the time of writing, and a few recent cases have developed respiratory catarrhal conditions either previous to the gastro-enteritis or immediately following the attack. Whether there is any significance in this it is too early to decide.

It is as yet impossible to define the incubation period with any real accuracy, but in the light of our present experience it would appear to range from thirty-six hours to seven days. Recently the cases have occurred in such a manner as to suggest that the illness is passed from patient to patient by contact infection, and we have noticed that men sleeping in beds adjacent to known cases have developed the gastro-enteritis during what we consider to be the incubation period. There is no epidemiological evidence to suggest infection from food, water, or milk as the causal factor. The outbreak has not been explosive in character and is obviously of a protracted type. 